\title{
THE CHURCH OF SANT'ANDREA IN BERGAMO: AN INTEGRATED SURVEY FOR KNOWLEDGE AND CONSERVATION
}

\author{
A. Cardaci ${ }^{1}$, G. Mirabella-Roberti ${ }^{1}$, P. Azzola ${ }^{1}$ \\ ${ }^{1}$ Dept. of Engineering and Applied Sciences, University of Bergamo, v.le Marconi, 5 - 24044 Dalmine, Italy \\ (alessio.cardaci, giulio.mirabella, pietro.azzola)@unibg.it
}

Commission II, WG II/8

KEY WORDS: Architectural survey, 3D laser-scanning, photogrammetric, conservation, historic building.

\begin{abstract}
:
The church dedicated to Sant'Andrea (St. Andrew) in 'Porta Dipinta' street in Bergamo city is a treasure that keep inside it a rich heritage of great historical and cultural value, both from the architectural and from the artistic point of view. Lacking of the façade (left unfinished), it is often neglected, despite being on the main road leading to the old town from 'Sant'Agostino' Gate. The approach to an historical building like this requires a multi-disciplinary integration, in order to join the technical competence of engineering sciences to the sensitivity of human and fine arts sciences. For a better understanding of the structural performances of the building, historical research, measurement survey, material and decay condition study have to complement each other.
\end{abstract}

\section{INTRODUCTION}

\subsection{The church of Sant'Andrea in Bergamo}

The research presented here belongs to a larger inter-disciplinary project aimed to support the knowledge and the valorisation of a monument quite often neglected also by Bergamo citizens, maybe for the external appearance, with an unfinished façade and without any bell-tower. Despite its position along the way from the 'Sant'Agostino' Gate and the heart of the old town (called high city, or 'Città Alta'), the church is nearly invisible to the tourists that ignore the rich architecture and the important paintings hided into the interior.

Recurring the 170th anniversary from the dedication of the church, the bishopric started a new phase for the valorisation and the conscious usage of the monument, with the active cooperation of the University of Bergamo. The church in fact is a prayer space for students, teaching staff and support staff of the University, and the basement, that was used as a theatre until the half of last century and disused for more than 50 years, recently has been renewed to host the Theatre University Centre but also conferences or cultural activities.

At the same time, historical and documental researches have been promoted, thanks to the recent reorganisation of the parish archives, together with a new metrical survey campaign, integrating indirect measurements by 3D laser-scanning systems and digital photogrammetry, for a better understanding of the building and its construction phases. The knowledge of an historical heritage is a vast process requiring different expertise, and the direct and analytical observation that a modern survey can efficiently support is an unavoidable step for the comprehension of design strategies initially adopted and the imperfections, anomalies and transformations occurred in practice.

\subsection{Historical and architectural notes}

The church of 'Sant'Andrea al Pozzo Bianco' occupies the place where the cemeterial, early-Christian 'basilica Sancti Andreae' was located, as testified by a document dated 785 a.D.. Following the damages produced by the construction of the new city walls by Venice Republic, the church was renewed and enlarged in 1592. After the abolition of the near parish of San Michele al pozzo bianco and the incorporation of its competences the request of a new, larger church lead the actual church, in neoclassical forms, erected in 1847 demolishing the previous one. A first project by architect Giacomo Romilli was presented in 1829, with a central plan and a hemispherical dome, and a façade with tympanum sustained by half-pilasters; but he church will be built following the project of the young architect Ferdinando Crivelli, that was in good relationship with Count Guglielmo Lochis, podestà of Bergamo at this time (Bocci 1997). Two projects of Crivelli are known, dating 1837 and 1840: there must be a third one, adopted for the building, but disappeared. Many historians have related the Crivelli's project to the church of Malta's knights in St. Petersburg, by the architect Giacomo Quarenghi, also coming from Bergamo: but many are the differences, in dimensions and proportions, and the dome, inspired by that of the Pantheon in Rome, is lacking in the Quarenghi's work (Bocci 1998). The actual church remained unfinished in the façade, lacking the pronaos made of Corinthian columns surmounted by a tympanum forwarded in Crivelli's project; nevertheless, it has been enriched in the interior by many precious paintings and an impressive decoration (Figure 2).

\subsection{The inner space}

The church is composed by a large central nave covered by barrel vaults, sustaining a dome nearly on the middle; two small lateral naves are separated by tall Corinthians columns, that ideally converge in the deep presbytery continuing the main nave. The light come from two large 'thermal' windows covered by arch just beneath the central dome that has a small oculus on the top (Figure 2). The modern survey techniques certainly support the knowledge of the artefact, but have to be always integrated with the traditional direct investigation, in order to correctly decode the richness of information contained in the documentation produced from data acquired by laser scanning and by digital photogrammetry, despite the high accuracy of metrical measurements (Docci 2009). Moreover, the high number of range scan and the high overlap of photographic shooting allowed reaching a high accuracy of graphical outputs with a 1:50 
resolution. So that it was also possible to investigate overall deformations (by means of contour maps at constant level, shape analysis of the dome, DTM of the floor) and the cracking pattern, outlining some incoming movement of the building and first deformation problems, as illustrated below in section 3 .

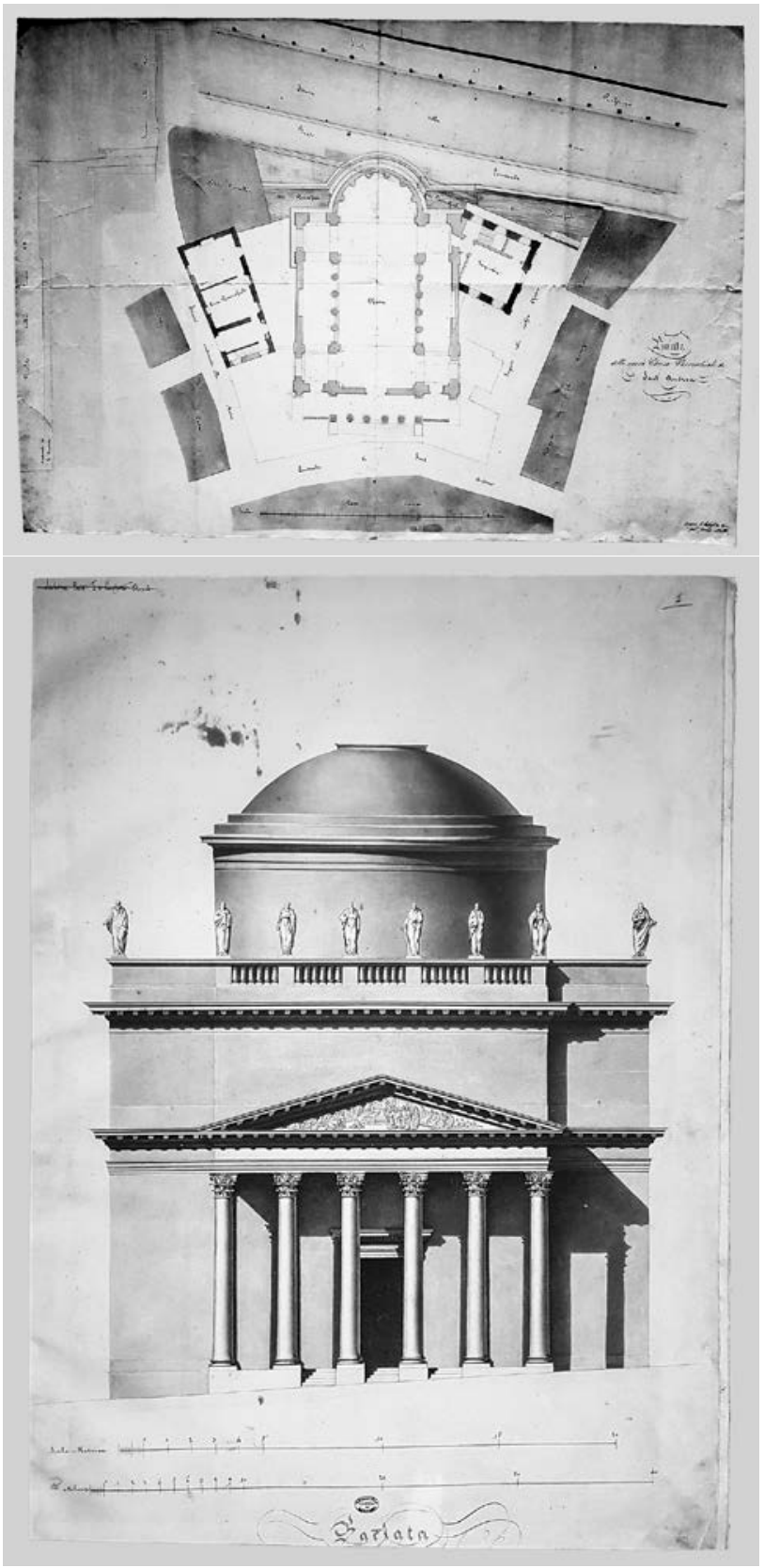

Figure 1. The second project of Ferdinando Crivelli for Sant'Andrea church.

\section{GEOMETRICAL SURVEY}

\subsection{The 3D laser scanning survey}

The 3D laser scanning survey relied on an existing topographic network outside the building, consisting of four vertexes with known coordinates (V1, V2, V3 and V4). The planning of acquisitions, carried out to record metric data without colour information, in order to optimize the time, had the aim of collecting the information in a well-organized, effective and computer-oriented manner.

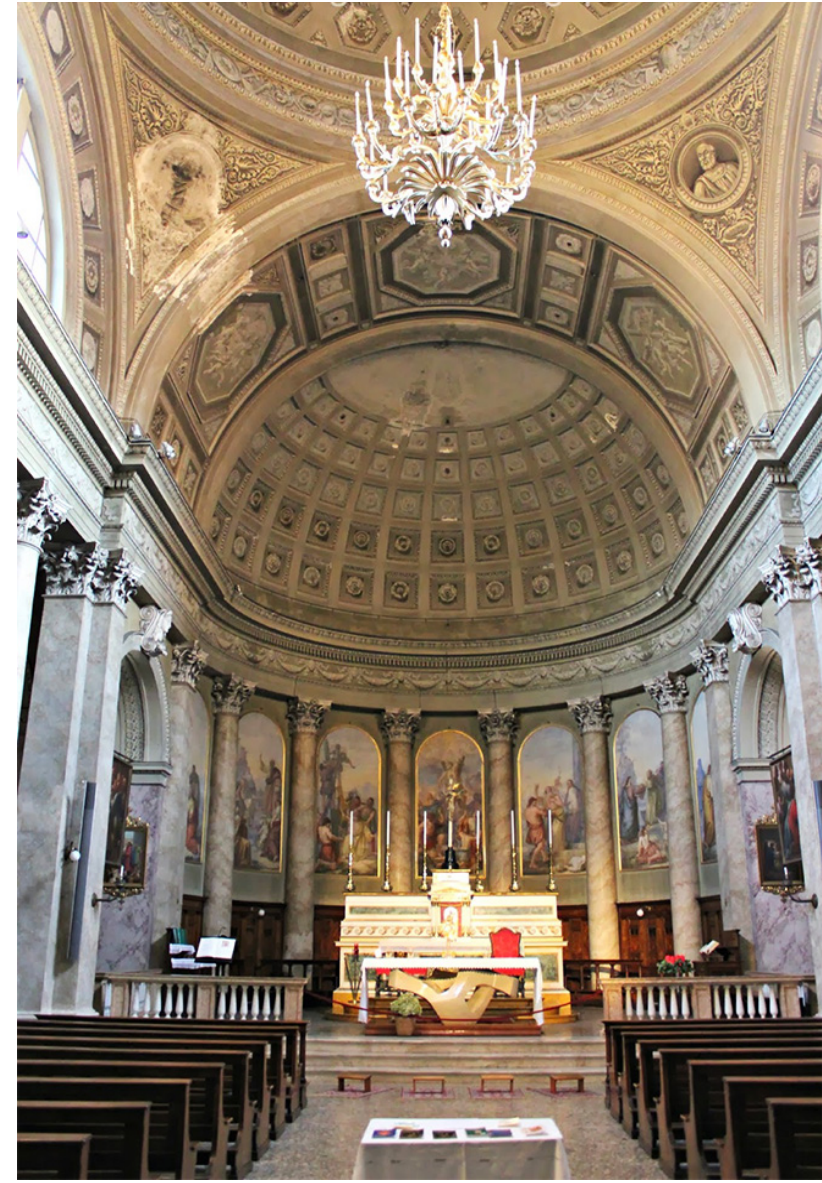

Figure 2. Interior view of the church of Sant'Andrea.

\subsection{The exterior survey}

The east façade is not visible because it is adjacent to other buildings, while an inaccessible site area to the west of the church has prevented the terrestrial acquisition with the circular method around the perimeter of the church, although there was the possibility of observing fixed points on high buildings in the area from both roads. This particular topographical situation implied to acquire the data mainly along the roads to the north (group 1, 21 scans) and to the south (group 2, 7 scans), creating connections to the west through the aforementioned fixed points and to the east by a walkway inside the rectory (group 3, 8 scans). A pedestrian passageway on the south side (group 4, 11 scans) at an intermediate level between those of via Porta Dipinta and viale delle Mura has also been used to strengthen the connection. At each entrance door to the church, a scan was performed in order to prepare the model for subsequent completion with the internal scans. 


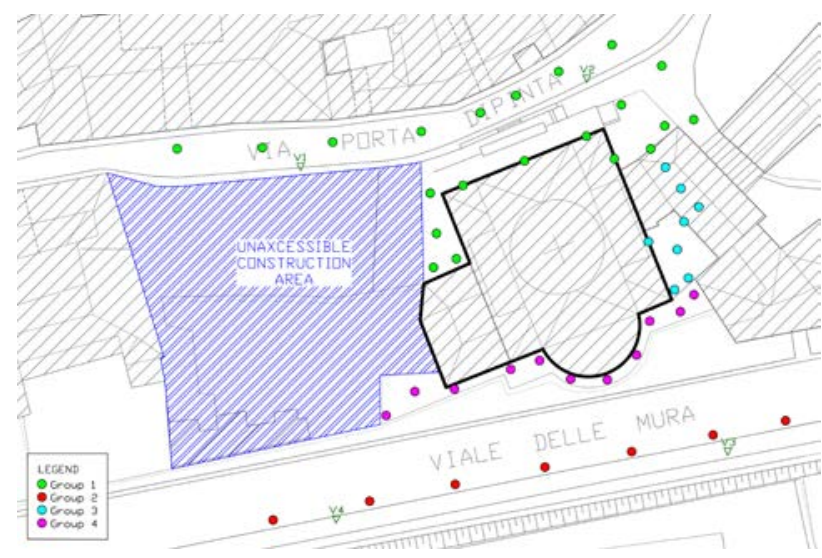

Figure 3. External positions for laser scanning acquisition.

The scanning parameters variables (angular resolution $r$, vertical and horizontal acquisition angle and control value) have been modified from time to time in order to guarantee for each scan the necessary level of Ground Sample Distance (GSD) according to the distance of the points to be acquired (surfaces and reference points), optimizing the time and resources employed in the acquisition phase:

$$
G S D=d \cdot \tan A R_{\text {laser }} \leq 3 \cdot 10^{-3} \mathrm{~m}
$$

where $\quad A R_{\text {laser }}=$ angular resolution

$\mathrm{d}=$ distance between camera and object

The scans processing, aimed to create a high precision point cloud of the urban context, has been performed with the ${ }^{\circledR} F A R O$ SCENE software, a scan registration software that features an implementation of the ICP algorithm as well as the option to use artificial targets. The software tools treated the raw scan data in order to improve their quality. By the identification in the individual scans, the coordinates of the topographic targets have been assigned. The scans have been placed in the group order described above with target-based alignment and then with the cloud-to-cloud registration.

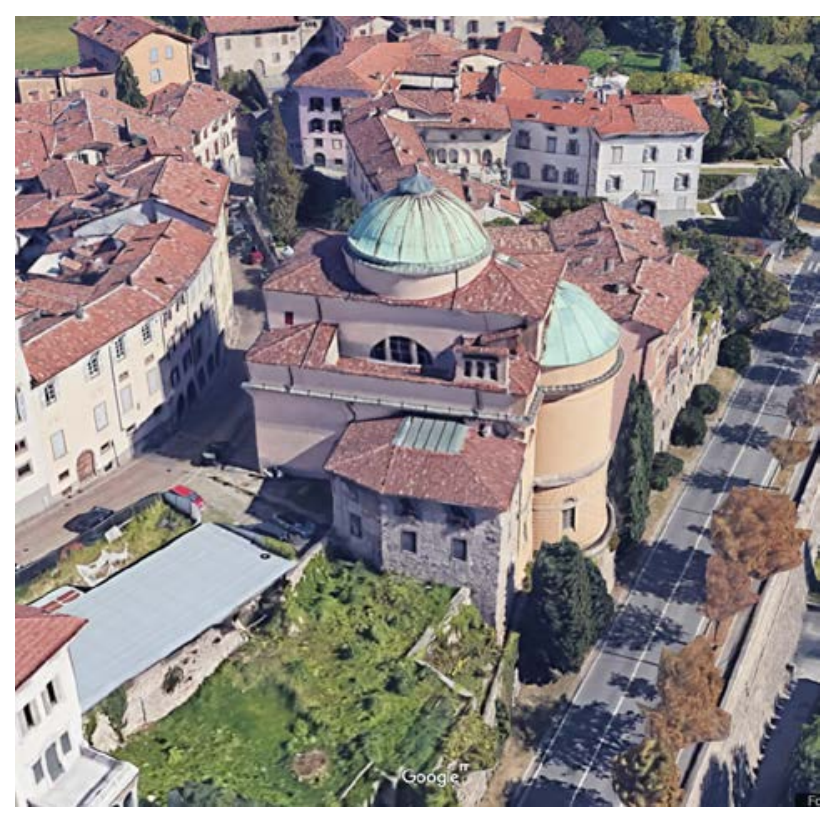

Figure 4. Aerial view of the church of Sant'Andrea.

\subsection{The interior survey}

A second survey phase, conducted in a similar way to the first both as regards the acquisition and processing criteria, acquired the internal part of the building. On the main floor, there are the three naves and the apse of the church (group 6) and the sacristy (group 7). On the ground floor, there is the corridor behind the stage of the theatre (group 8) that connects between them the two stairs descending to the theatre hall (group 9). Finally, the ancient crypt is present at the intermediate level of the stairs with the annexed under stair cupboard (group 10).

The mutual alignment from cloud to cloud of the ten rigid groups constituted a rough positioning of the single scans since the model presented macroscopic alignment errors greater than the statistical values calculated in the report produced by ${ }^{\circledR F}$ FRO SCENE. However, this elaboration phase was necessary to manage the large number of scans. The result of laser scanning processing has been optimized extracting all scans from the group folders and performing a final cloud-to-cloud registration making a large number of iterations. The overall improvement is confirmed by the result of the alignment report. There are still rare cases of misalignment of some scans, probably due to accidental errors during the acquisition phase.

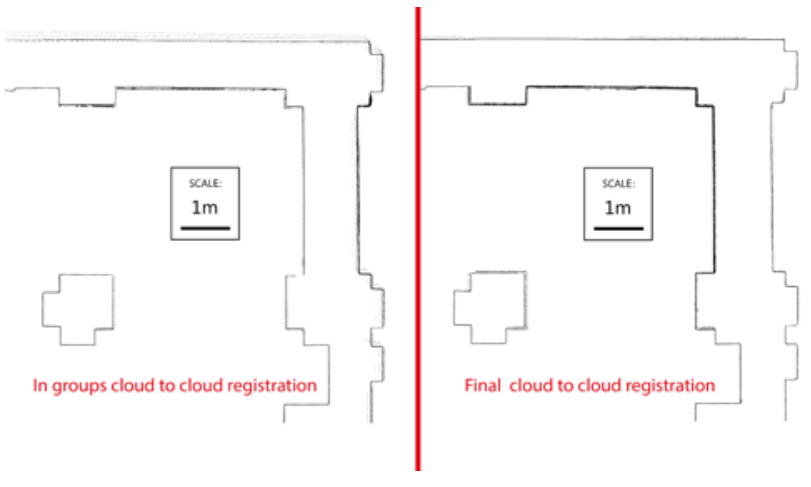

Figure 5. Alignment results before and after the final registration

The result of laser scanning processing is a project cloud with homogenized point density subsampled at $3 \mathrm{~mm}$ in grey tones according to the reflectance value, which allowed the extraction of the typical technical drawings for the building (plans, sections and elevations).

\subsection{The photogrammetric survey}

The laser scanning geometric description of the surfaces was then combined with the photogrammetric survey aimed at obtaining a detailed chromatic mapping of the floor, of the walls, of the vaults inside the naves, as well as of the unfinished façade.

The photogrammetric modelling is a powerful tool for increasing knowledge. The correct identification of its objective defines the requirements that the virtual model must guarantee. Differently from the laser-scanning survey, which is geometrically reliable, the photogrammetric survey must guarantee the correct chromatic representation. In this specific case study, a precise evaluation of the state of conservation and degradation of the surfaces is sought (e.g. stains and chromatic alterations, efflorescence, cracks). In view of this need, the Ground Sample Distance (GSD) assured by the data set acquired for the vault covering the nave was evaluated. It consists of a series of vertical axis pictures acquired from the ground using a Canon EOS 5D reflex camera with both $24 \mathrm{~mm}$ and $70 \mathrm{~mm}$ lenses, in order to 
combine the overall photographic framing (useful for the 'structure from motion' phase) and the high level of detail offered by telephoto lens.

Assuming the optical axis of the camera perpendicular to the photographed surface, the two angular resolutions $A R$ are respectively:

$$
A R_{24 \mathrm{~mm}}=1.29 \mathrm{rad} ; \quad A R_{70 \mathrm{~mm}}=5.03 \cdot 10^{-1} \mathrm{rad}
$$

it results, for $24 \mathrm{~mm}$ lenses:

$$
\begin{aligned}
& G S D_{24 \text { (nave })}=\left(h_{v}-h_{a}\right) \cdot \tan A R_{24}=3.74 \cdot 10^{-3} \mathrm{~m} \\
& G S D_{24(\text { dome })}=\left(h_{d}-h_{a}\right) \cdot \tan A R_{24}=5.58 \cdot 10^{-3} \mathrm{~m}
\end{aligned}
$$

and for $70 \mathrm{~mm}$ :

$$
\begin{aligned}
& G S D_{70(\text { nave })}=\left(h_{v}-h_{a}\right) \cdot \tan A R_{70}=1.28 \cdot 10^{-3} \mathrm{~m} \\
& G S D_{70(\text { dome })}=\left(h_{d}-h_{a}\right) \cdot \tan A R_{70}=1.91 \cdot 10^{-3} \mathrm{~m}
\end{aligned}
$$

where: $\quad h_{a}=1.50 \mathrm{~m}$ is the acquisition instrumental height, $h_{v}=15.50 \mathrm{~m}$ is the the vault of the nave height,

$h_{d}=22.40 \mathrm{~m}$ is the top of the dome height.

Calculating a weighted average, assuming 0.60 weight for the vault of the nave and 0.40 for the dome top, we obtain:

$$
\begin{aligned}
G S D_{24 m m} & =4.48 \cdot 10^{-3} \mathrm{~m} ; \\
G S D_{70 \mathrm{~mm}} & =1.53 \cdot 10^{-3} \mathrm{~m}
\end{aligned}
$$

These values are interesting since they indicate that the combination of the images acquired with the two lenses allows obtaining a virtual model adequate to the survey of the crack pattern, having a higher level of detail than that is normally detectable by human vision, whose angular resolution on average it is worth $A R_{h v}=1.70 \cdot 10^{-4} \mathrm{rad}$.

$$
\begin{aligned}
& G S D_{\text {optic }(\text { nave })}=\left(h_{v}-h_{a}\right) \tan A R_{h v}=3.55 \cdot 10^{-3} \mathrm{~m} \\
& G S D_{\text {Optic }(\text { dome })}=\left(h_{d}-h_{a}\right) \tan A R_{h v}=2.38 \cdot 10^{-3} \mathrm{~m}
\end{aligned}
$$

Calculating the weighted average as above, we obtain

$$
G S D_{\text {Optic }}=3.08 \cdot 10^{-3} \mathrm{~m}>G S D_{70 \mathrm{~mm}}
$$

Additional images were acquired with camera axis tilted about $15^{\circ}$ from the vertical in both directions. This value was chosen to improve the correct modelling of the existing 3D elements (overhangs, cornices, column capitals). A similar procedure was carried out for the walls setting (horizontal camera axis), as was for the floor (sub-horizontal camera axis).

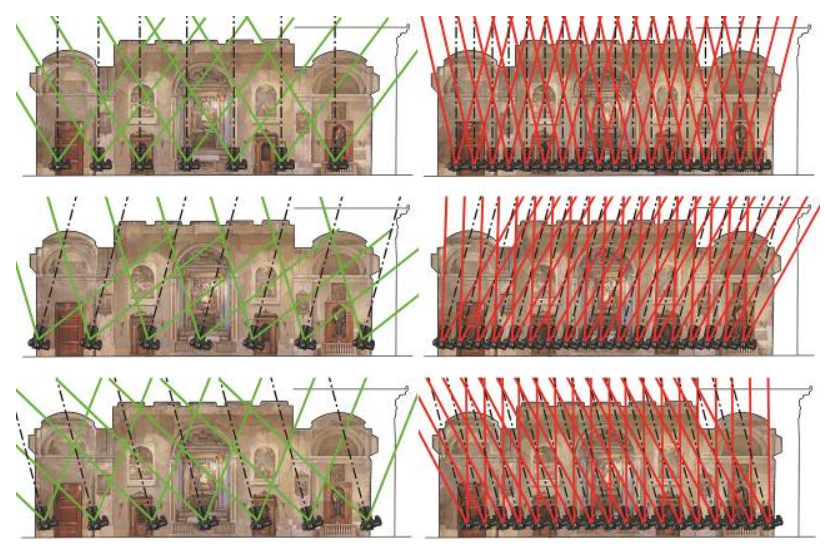

Figure 6. Camera axis direction, field of view and overlapping length in case of $24 \mathrm{~mm}$ lens (left) and $70 \mathrm{~mm}$ lens (right)
An overlapping of contiguous shots varying between $60 \%$ and $80 \%$ of the length determined the acquisition step, calculated from time to time, was respected.

The photographic acquisition phase needed to obtain the maximum field depth choosing the diaphragm aperture in according to the optics used and the focusing distance of the framed subject. The resulting shutter times required the use of a stand with a remote control. The natural lighting coming from the openings combined with the halogen lamps lighting determined a condition of non-optimal light characterized by very bright parts and others almost dark. Therefore each image was acquired in RAW format with auto exposure bracketing ( $0 \pm 1$ 1/3 stop), the colour temperature of the light was compensated by colourchecker profile application and it was edited in TIF format in order to produce High Dynamic Range (HDR) images with ®Photomatix Pro software. Improved image quality positively affects the resulting 3D textured models (Kontogianni et al., 2014), so this procedure aims at improving the matching of images in the framework of the SFM/image matching 3D modelling pipeline (Guidi et al., 2014). On the other hand, HDRI is a time consuming procedure, still less than digital post processing of LDR images, which does not always have satisfactory results (Ntregka et al., 2013).

The photogrammetric process was performed in ${ }^{\circledR} 3 D F L O W$ Zephyr Aerial, following the typical workflow that leads from 2D images to the textured mesh. The geo-referencing of the photogrammetric model and the simultaneous optimization of the alignment of the 2D images took place by assigning the spatial coordinates of six check-board topographic targets, obtained from the laser-scanning model.

\subsection{Integrating the two surveys with topographic reference in ${ }^{\circledR 3 D F L O W}$ Zephyr Aerial}

The combination of the two systems in a single model intends to provide a reliable datum both for the geometric precision and for the chromatic characterization of the surfaces. This result will be the reliable support for each subsequent study. Using the ®3DFLOW Zephyr Aerial software, the photogrammetric point cloud was combined with the laser scanning cloud by the six control points and subsequently the ICP algorithm was employed to minimize the difference between two point clouds position and scale. The reference system easily defined projection plans for the creation of drawings useful for the subsequent study and the mapping of degradation according to the methodological and graphical criteria currently considered most effective. In particular, the floor plan and the hyposcopic plan of the roof, the facades of the internal walls and of the external façade have been obtained; a series of vertical sections instead highlighted the complex articulation of the underground spaces in addition to offer useful tools to estimate the dimensions of the structural elements.

\section{STRUCTURAL CONSIDERATIONS}

The church stands on a natural slope: its main façade lays upstream, on via Porta Dipinta, the apse part instead stays downstream towards viale delle Mura and Venetian walls. A nonnegligible crack pattern can be observed, probably due to the differential settlement with downward movement of the foundations; therefore, a laser-scanning survey could be used to verify the horizontality of the floor and the verticality of the dome axis, as well as the deformations of the barrel vaults and dome structures. A few targets measured with a theodolite may notably stabilize the network geometry, providing additional information to check registration quality. However, a combined solution based on a reduced target number in strategic location and planes may simplify on-site work and improve the overall metric 
accuracy (Wujanz et al., 2019). It makes use of the existing six reflective targets already present for photogrammetry phase, but this is based on a total-station survey, more accurate and precise compared to that was used in the previous phases which was based on four urban topographic vertices. The polar coordinates of the new local reference system, converted into Cartesian coordinates, were assigned to the targets of the laser-scanning model.

The point cloud of the dome was intersected with horizontal planes with constant pitch through an automated procedure with the software ${ }^{\circledR} 3 \mathrm{DFLOW}$ Zephyr Aerial. The interpolation of the centres of the circumferences resulting from the intersection of horizontal planes with the hemispherical surface of the dome defined the inclination of its axis (Artese et al. 2019) that resulted equal to $0.86^{\circ}$ in the direction of the apse (Figure 11).

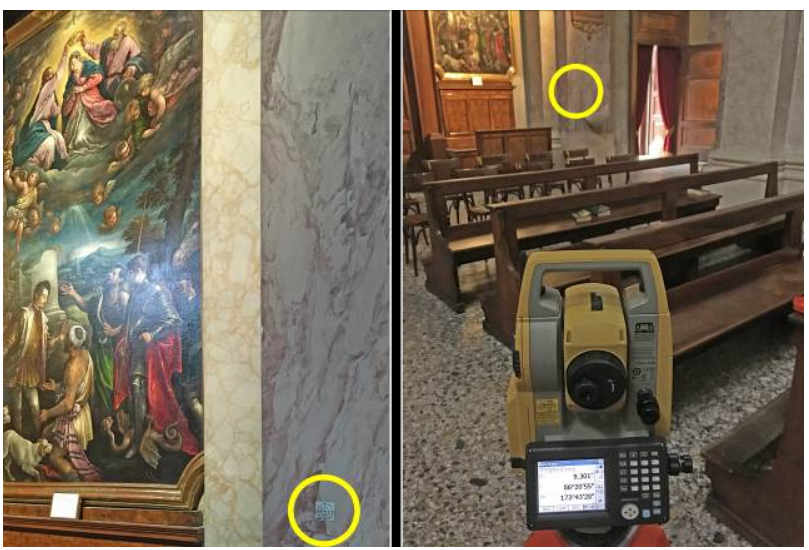

Figure 7. Internal church total-station network survey

The trend of the surface obtained from the points belonging to the interior floor (DSM) shows also a slight slope in South-West direction (Figure 12). The two combined observations could be a hint suggesting a possible roto-translation towards the downstream of the whole complex. Moreover, a deformation of the barrel vaults in correspondence with the arches sustaining the central dome is also evident, confirmed by the cracking pattern on the crown of this arches and a sort of 'punching effect' on the lateral naves (Figure 10).

\section{CONCLUSIONS}

Historical research confirmed the existence of a solid and mature design at the base of the spatial organization of the church. Subsequent metric and material investigations carried out on the building suggested a reflection on the importance of the comprehension of the language of historical architecture. The use of modern instrumentation based on relevant technology can undoubtedly facilitate the understanding of this language, that anyway requests knowing the rules underlying its conception and construction.

The modern techniques of instrumental investigation and, their integration with traditional direct observation certainly favoured the new activities of understanding the architectural organism. The actual survey rests on many acquisitions organized according to a strict scheme designed to obtain complete and homogeneous $3 \mathrm{D}$ models. The high number of range scans and the considerable overlapping surfaces of the photographic pictures limited the alignment and recording inaccuracies, keeping them below the graphic rendering tolerance specified for the 1:50 scale.

The high accuracy of the results allowed - by means of series of sections at constant level, representation of the verticality variation, DSM analysis - the assessments on the deformations and on the crack pattern, highlighting the initial failures related both to a subsidence of the embankment, and to the high weight of the dome.

Today the temple manifests, therefore, the first sufferings, both due to the ancient design choices, and related to the passage of time and to a lack of constant and continuous maintenance. The survey carried out constitutes a singular and conscious document that reflects the current state, representing the physical and pathological consistency of the monument. It is therefore an instrument of knowledge for the conservation of an architecture, which, although wrongly considered minor, is always unique and irreproducible.
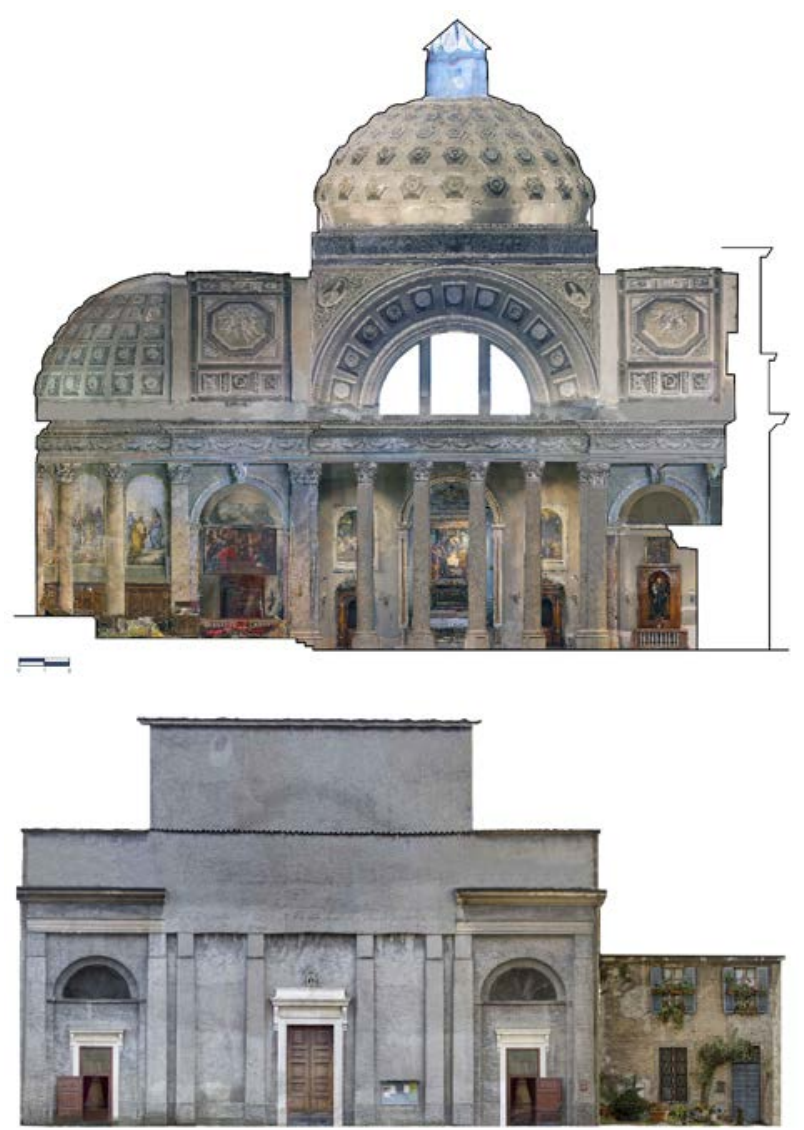

scenosurea

Figure 8. Orthographic projection of the longitudinal section (top) and of the façade (bottom).

\section{ACKNOWLEDGEMENTS}

The authors wish to give a special thanks to Don Giovanni Gusmini, regent of the church of St. Andrea, for his friendly support in the research and for the precious collection of documents regarding the church. The enthusiastic contribution of all the students of the master class in Survey and Conservation of Architecture of the University of Bergamo in A. Y. 2018-2019 has been greatly appreciated. 


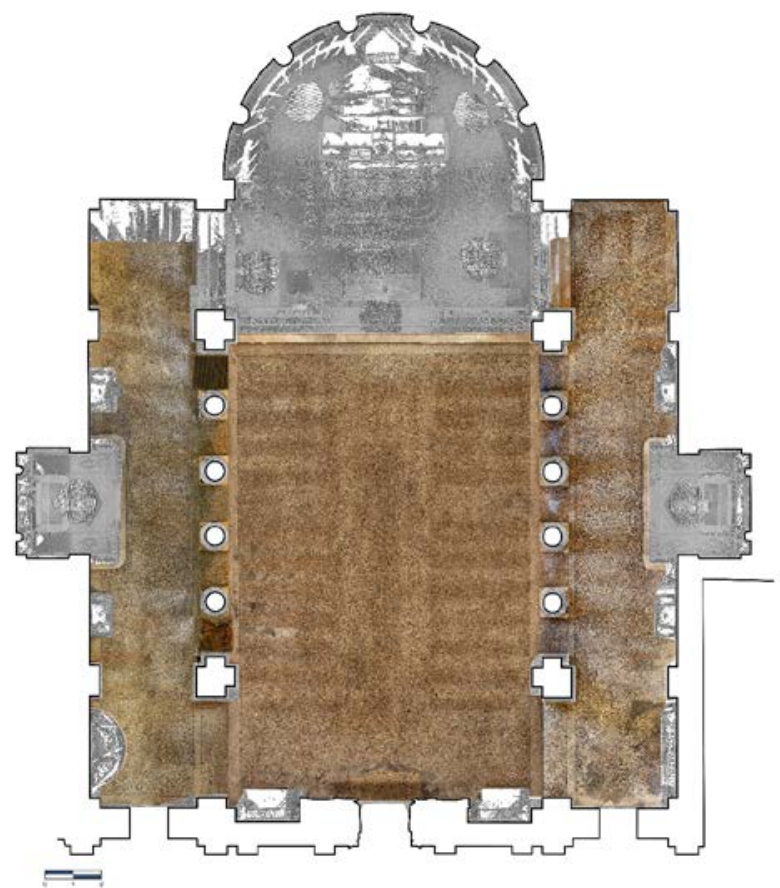

Figure 9. Internal plan with the photogrammetric floor texture

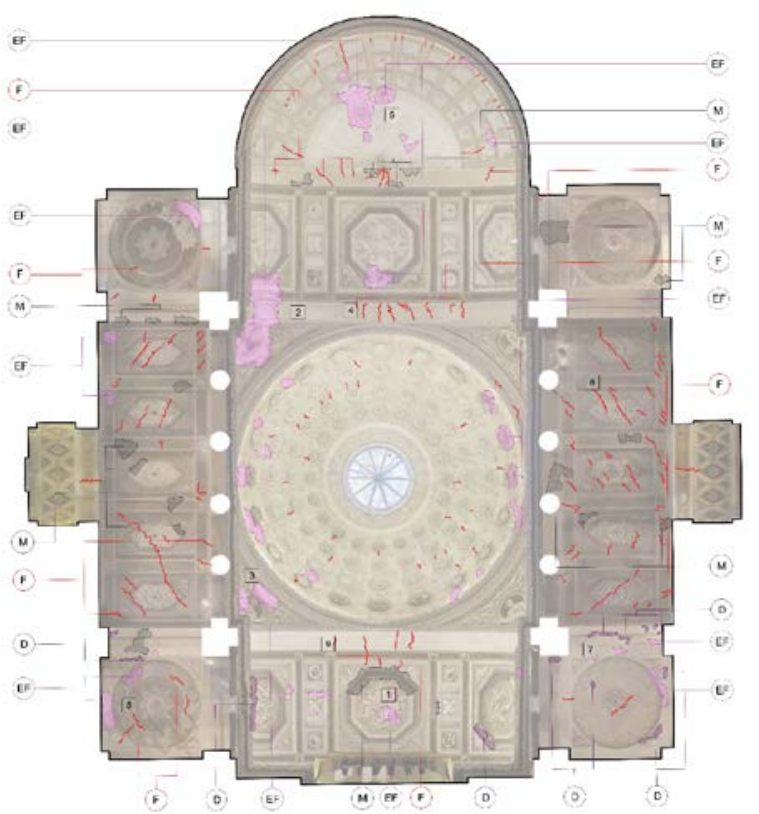

Figure 10. Hyposcopic view of the ceiling with the projection of the vaults and the domes: cracking pattern and decay mapping.
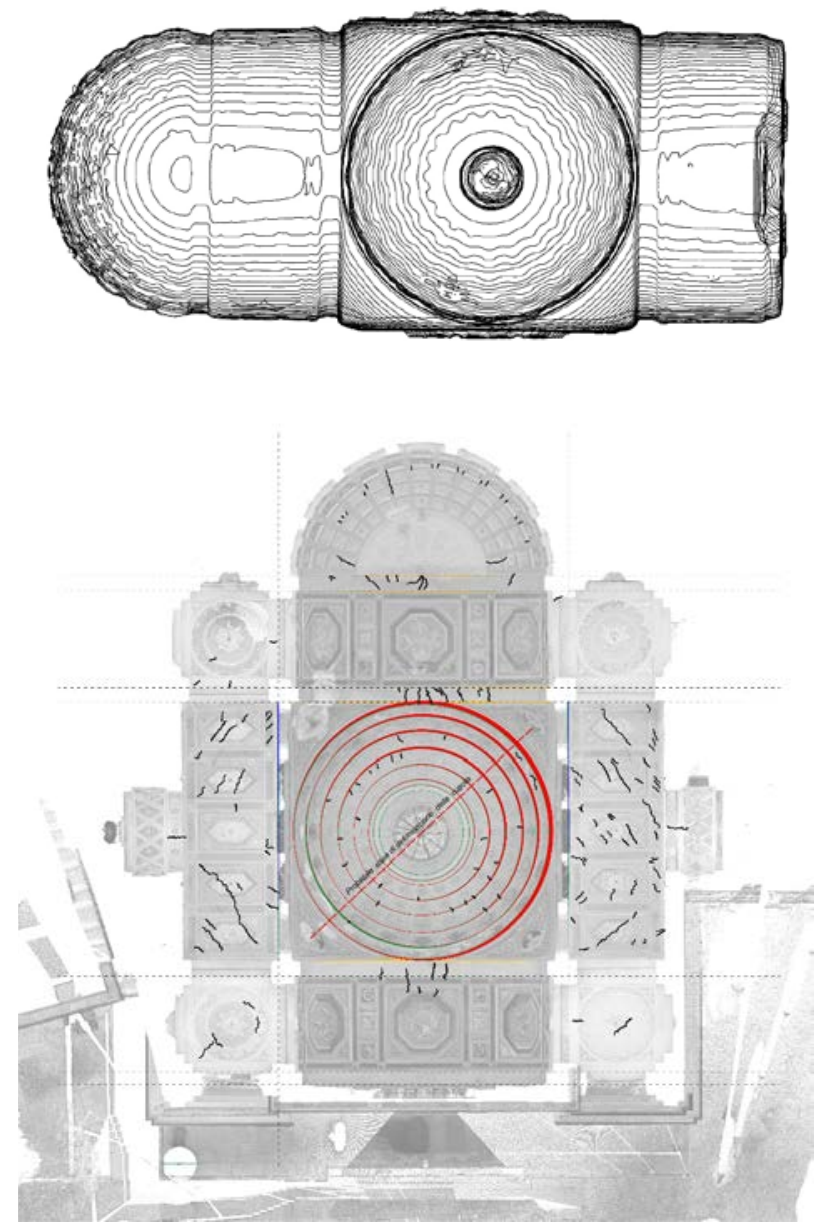

Figure 11. Geometrical analysis of the vaults and the dome: contour map of levels (top), hyposcopic plan (bottom) with cracking pattern and dome deformation representation.

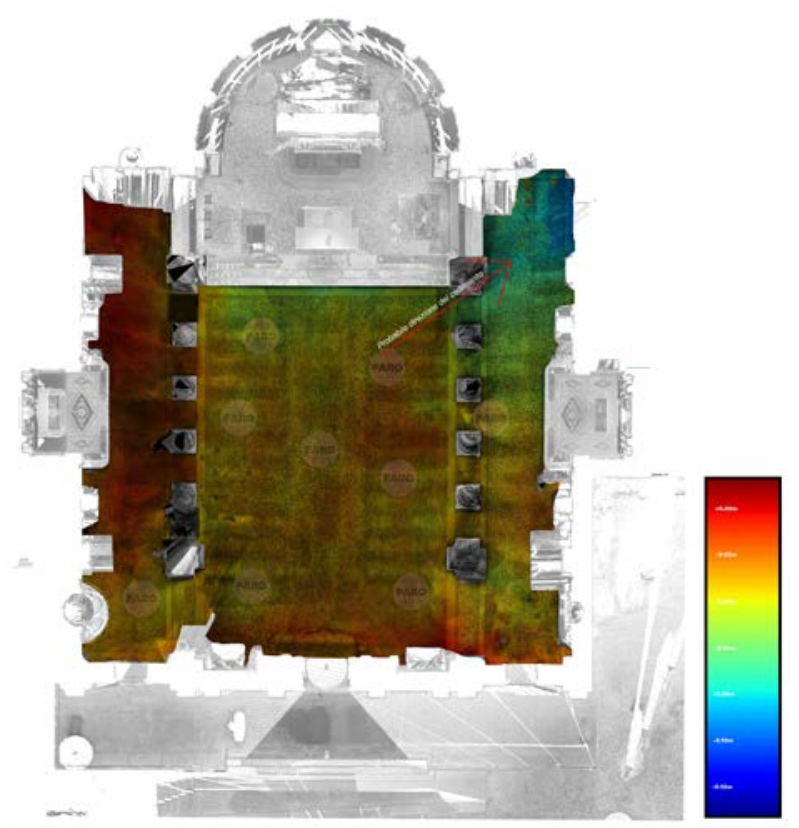

Figure 12. Digital Elevation Model of the internal floor surface 


\section{REFERENCES}

Artese, S., Lerma, J. L., Aznar Molla, J., Sánchez, R. M. and Zinno, R., 2019. Integration of surveying techniques to detect the ideal shape of a dome: the case of the escuelas pías church in Valencia. In: Int. Arch. Photogramm. Remote Sens. Spatial Inf. Sci., XLII-2/W9, 39-43, https://doi.org/10.5194/isprs-archivesXLII-2-W9-39-2019.

Bocci, B., 1997. La chiesa di Sant'Andrea a Bergamo dell'architetto Ferdinando Crivelli. Bergomum, 92, pp. 123-144.

Bocci, B., 1998. Ferdinando Crivelli (1810-1855) architetto neoclassico bergamasco. Atti dell'Ateneo di Scienze, Lettere e Arti di Bergamo, LIX, (1995-1996), pp. 75-93.

Cardaci, A., Mirabella Roberti, G. and Versaci, A., 2019. The integrated 3D survey for planned conservation: the former church and convent of Sant'Agostino in Bergamo. In: Int. Arch. Photogramm. Remote Sens. Spatial Inf. Sci., XLII-2/W9, 235242, https://doi.org/10.5194/isprs-archives-XLII-2-W9-2352019.

Docci, M., Maestri, D., 2009. Manuale di rilevamento architettonico e urbano. Bari: Laterza.

Guidi, G., Gnizzi, S., Micoli, L., 2014. Image pre-processing for optimizig automated photogrammetry performances. In: ISPRS Technical Commission V Symposium (Vol. 2, pp. 145-152). ISPRS.

Kontogianni, G., Georgopoulos, A., 2014. Investigating the effect of HR images for the 3D documentation of cultural heritage. In: Proc. of the $5^{\text {th }}$ International Conference on Cultural Heritage, Lemessos, Cyprus (pp. 3-8).

Ntregka, A., Georgopoulos, A., Santana Quintero, M., 2013. Photogrammetric exploitation of HDR images for cultural heritage documentation. ISPRS Annals of the Photogrammetry, Remote Sensing and Spatial Information Sciences, 5, W1.

Wujanz, D., Barazzetti, L., Previtali, M. and Scaioni, M., 2019. A comparative study among three registration algorithms: performance, quality assurance and accuracy. In: Int. Arch. Photogramm. Remote Sens. Spatial Inf. Sci., XLII-2/W9, 779786, 2019. https://doi.org/10.5194/isprs-archives-XLII-2-W9779-2019. 